\title{
A new home for organic chemistry in Austria: the workgroup organic chemistry of the Austrian Chemical Society
}

\author{
Nuno Maulide ${ }^{1} \cdot$ Michael Schnürch $^{2}$
}

Received: 22 November 2016/ Accepted: 24 November 2016/Published online: 7 December 2016

(C) Springer-Verlag Wien 2016

Dear readers,

The present issue of Chemical Monthly is dedicated to a special event: the inauguration of the newly created Workgroup Organic Chemistry of the Austrian Chemical Society (GÖCH) in January 2016. With this workgroup, which replaces and incorporates the former Workgroup Chemistry of Heterocycles, there is a clear aim of uniting the practitioners of Organic Chemistry in Austria, in all its facets and diversity. The kick-off event of the Workgroup, held at the Johannes-Kepler-University of Linz in March 2016, could not have sent a stronger signal in this direction: alongside the plenary speaker Prof. Thorsten Bach (TU Munich, Germany), four colleagues representing the cities providing academic programs in Organic Chemistry of the country (Graz, Prof. O. Kappe; Innsbruck, Prof. R. Micura; Linz, Prof. M. Waser; Vienna, Prof. P. Kosma) presented exciting research work ranging from flow chemistry to nucleic acid chemistry, passing by carbohydrate synthesis and asymmetric organocatalysis! The attendance of more than 120 participants who completely filled the lecture hall also showcased the vibrance and dynamic of the organic chemistry community, from academia to industry.

Nuno Maulide

nuno.maulide@univie.ac.at

$\bowtie$ Michael Schnürch

michael.schnuerch@tuwien.ac.at

1 Institute of Organic Chemistry, University of Vienna, 1090 Vienna, Austria

2 Institute of Applied Synthetic Chemistry, Vienna University of Technology, 1060 Vienna, Austria
It is, therefore, with great pleasure that GÖCH and Springer decided to embrace the momentum gathered and further promote the activities of this young Workgroup with this special issue. It includes invited contributions from colleagues in a broad spectrum of research activities, which illustrate the diversity of the field.

The guest editors of this issue wish to express their gratitude to the editorial executives at Springer for supporting the creation of the Workgroup Organic Chemistry through this initiative, and hope that this tribute to what remains one of the key pillars of modern chemistry will inspire future special issues within Chemical Monthly.

With these clear indicators of a strong drive and support, the Workgroup has also created an annual named-lectureship in honour of the pioneering organic chemist Adolf Lieben, the first edition (2016) of which was awarded to Prof. Alois Fürstner (MPI Mülheim, Germany). The selected "Lieben Lecturer" will typically spend close to a week in Austria delivering in total up to four lectures at some of our Universities. It is our particular pleasure to announce here the upcoming Adolf Lieben Lectureship 2017: Prof. Varinder Aggarwal from the University of Bristol will make his Tour d́Autriche in March 2017 and will give lectures on the following dates:

20.3.2017, 08:30, Hörsaal H (Ulrich Santner), Chemiegebäude der TU Graz, Stremayrgasse 9

21.3.2017, 17:30, TUtheSky Lounge, Getreidemarkt 9, Chemiehochhaus, 11.Stock, 1060 Wien

23.3.2017, 17:15, CCB, Raum L.01.220, Innrain 80-82, 6020 Innsbruck

Organic chemists in Austria, unite!

Sincerely,

Nuno Maulide, Michael Schnürch 